\title{
Determination of Trace Elements in Lead and Lead- based Alloys by Inductively Coupled Plasma Optical Emission Spectrometry After Separation of Lead as Lead Chloride Fluoride Precipitate
}

\author{
G. Venkateswarlu, A. C. Sahayam ${ }^{a *}$, S. C. Chaurasia, and Chintamani Das ${ }^{b}$ \\ ${ }^{a}$ National Centre for Compositional Characterisation of Materials (CCCM) \\ BARC, ECIL (P.O), Hyderabad-500 062, India \\ ${ }^{b}$ Fusion Reactor Materials Section, BARC, Mumbai- 400 085, India
}

\section{INTRODUCTION}

Lead is used in batteries, TV screens, as shielding material in nuclear reactors, and also in the manufacture of alloys such as $\mathrm{PbBi}$ and PbLi (1-3). Lead-bismuth eutectic $(\mathrm{PbBi})$ is a potential candidate material for spallation target and coolant in accelerator-driven systems (ADS) $(4,5)$. Similarly, leadlithium eutectic ( $\mathrm{PbLi})$ is proposed for use as multiplier, breeder, and coolant in fusion reactors (6-8). The presence of impurities limits their utility, and hence, it is important to determine trace elements present in these materials as a quality check. Direct determination of impurities after dissolution of the sample by ICP-based techniques is difficult due to matrix interferences, both spectroscopic and non-spectroscopic in nature (9). Solid state techniques such as spark source mass spectrometry, though reported for the determination of impurities in lead, require matrixmatched standards (10). Hence, for accurate determinations, the matrix element needs to be separated from the trace impurities.

Normally, $\mathrm{Pb}$ is separated from trace impurities as $\mathrm{PbCl}_{2}$ precipitate (11). However, some of the hydrolyzable elements such as $\mathrm{Nb}$, $\mathrm{Sb}, \mathrm{Sn}, \mathrm{Ta}$, and $\mathrm{Ti}$ are not recovered by this procedure. Solvent extraction and ion exchange procedures are already developed, but they are tedious, time-consuming, and all of

*Corressponding autbor

E-mail: acs10@rediffmail.com

Tel: 91-40-27121365

Fax: 91-40-27125463

\section{ABSTRACT}

A method has been developed for the separation of $\mathrm{Pb}$ from trace impurities such as $\mathrm{Nb}, \mathrm{Ni}$, $\mathrm{Sb}, \mathrm{Sn}, \mathrm{Ta}$, and Ti for their determination in $\mathrm{Pb}, \mathrm{PbLi}$, and $\mathrm{PbBi}$ alloy samples. Lead was separated as chloride fluoride ( $\mathrm{PbClF}$ ) precipitate. The method also enables the determination of hydrolyzable elements which are otherwise not recovered. The separation of $\mathrm{Pb}$ was found to be $99.5 \%$, whereas the recovery of impurities was in the 82-94\% range. Matrix-free solutions were analyzed for $\mathrm{Nb}, \mathrm{Ni}, \mathrm{Sb}, \mathrm{Sn}, \mathrm{Ta}$, and $\mathrm{Ti}$ by inductively coupled plasma optical emission spectrometry (ICP-OES). The method was applied for the analysis of $\mathrm{Pb}, \mathrm{PbLi}$, and $\mathrm{PbBi}$ alloy samples. Relative standard deviations were in the $1.8-10.2 \%$ range and the process blank levels were at the lower $\mu \mathrm{g} / \mathrm{g}$ level. the elements of interest cannot be separated and determined using a single separation procedure (1214). Therefore, a better alternative to the existing procedures is necessary.

The procedure reported in the present study deals with the separation of $\mathrm{Pb}$ as chloride fluoride ( $\mathrm{PbClF}$ ) precipitate from $\mathrm{Pb}, \mathrm{PbLi}$, and $\mathrm{PbBi}$ samples. Matrix-free supernatants are analyzed for $\mathrm{Nb}$, $\mathrm{Ni}, \mathrm{Sb}, \mathrm{Sn}, \mathrm{Ta}$, and Ti by inductively coupled plasma optical emission spectrometry (ICP-OES). The procedure is applied to the analysis of $\mathrm{Pb}$ and $\mathrm{PbLi}$, PbBi alloy samples. A comparison between $\mathrm{PbCl}_{2}$ and $\mathrm{PbClF}$ methods is also reported.

\section{EXPERIMENTAL}

\section{Instrumentation}

An inductively coupled plasma optical emission spectrometer Model No. JY-2000, equipped with a $40.68 \mathrm{MHz}$ radio frequency generator, was used for these studies and determinations (Jobin Yvon, Horiba, France). The operating parameters used are listed in Table I.

TABLE I. ICP-OES Operating Parameters

\begin{tabular}{ll} 
Instrument & JY 2000 Sequential ICP-OES Spectrometer \\
RF Power & $1 \mathrm{~kW}$ at $40.6 \mathrm{MHz}$ \\
Plasma gas flow rate & $12 \mathrm{~L} \mathrm{~min}^{-1}$ \\
Nebulizer gas flow rate & $0.1 \mathrm{~L} \mathrm{~min}^{-1}$ \\
Sample uptake rate & $1.2 \mathrm{~mL} \mathrm{~min} \mathrm{~mL}^{-1}$ \\
Slit width & $20 \mu \mathrm{m} / 20 \mu \mathrm{m}$ (Entrance/Exit) \\
Monochromator & $0.64 \mathrm{~m}$ focal length, \\
& 2400 groves/mm \\
& Czerny Turner mounting \\
\hline
\end{tabular}




\section{Reagents}

Analytical reagent grade chemicals were used throughout. Pure water $(18 \mathrm{M} \Omega \mathrm{cm})$ was prepared by passing potable water through a mixed-bed ion exchanger and then through a Millipore ${ }^{\circledR}$ Milli- ${ }^{\mathrm{TM}}$ system. The standard solutions of the metals were procured as multielement standard solution from E. Merck, Germany. Pb was procured from E. Merck, Germany, PbLi and $\mathrm{PbBi}$ samples were purchased from local suppliers.

\section{Analytical Procedure}

$\mathrm{Pb}$, PbLi, or PbBi alloy (0.5 g) was dissolved in $3 \mathrm{~mL}$ nitric acid $\left(\mathrm{HNO}_{3}\right)$ and $2 \mathrm{~mL}$ hydrofluoric acid (HF) in a water bath and diluted to $20 \mathrm{~mL}$. To the solution, $2 \mathrm{~mL}$ hydrochloric acid $(\mathrm{HCl})$ was added to precipitate $\mathrm{Pb}$ as $\mathrm{PbClF}$ and was then diluted to $25 \mathrm{~mL}$. The resultant precipitate was centrifuged and the supernatant was analyzed for $\mathrm{Nb}, \mathrm{Ni}, \mathrm{Sb}, \mathrm{Sn}, \mathrm{Ta}$, and Ti by ICPOES. To verify the recoveries of the analytes, sample solutions spiked with traces of standard solutions of the analytes of interest were treated as mentioned above and analyzed by ICP-OES. The process blanks were also prepared as mentioned above without sample. The percentage recoveries were calculated by comparing the signal of the pure standards and those of the spiked standards.

The above procedure was repeated without $\mathrm{HF}$ to compare the recoveries of the analytes with and without HF. The procedure was applied for the analysis of $\mathrm{Pb}$, $\mathrm{PbLi}$, and PbBi alloys. The same ICP-OES system (JY-2000) was used for the measurements. The calibration standards used for quantification were in the $0.5-5 \mu \mathrm{g} / \mathrm{mL}$ range and external calibration was used for quantification.

\section{RESULTS AND DISCUSSION}

The simplest procedure for the separation of $\mathrm{Pb}$ from trace impurities is precipitation as $\mathrm{PbCl}_{2}$. Hence, lead samples dissolved in $\mathrm{HNO}_{3}$ were analyzed by trace impurities after separation of $\mathrm{Pb}$ as $\mathrm{PbCl}_{2}$. However, the recoveries of $\mathrm{Nb}, \mathrm{Sb}, \mathrm{Sn}, \mathrm{Ta}$, and Ti were less and found to be decreasing with time due to hydrolysis. Hence, quantification could not be performed. The elements whose recoveries were found to be poor are known to form stable fluorides.

To improve the recoveries, the sample was dissolved in $\mathrm{HNO}_{3}$ and HF. Precipitation was carried out using $\mathrm{HCl}$ in the presence of $\mathrm{HF}$, leading to lead chloride fluoride (PbClF) precipitation. This procedure ensures the complete precipitation of lead and also avoids hydrolysis of the elements mentioned above.

A comparison of recoveries in the presence and absence of $\mathrm{HF}$ is shown in Table II. It can be seen that the recoveries of $\mathrm{Nb}, \mathrm{Ni}, \mathrm{Sb}$, Sn, Ta, and Ti were found to be near quantitative when $\mathrm{Pb}$ was precipitated as $\mathrm{PbClF}$ compared to those obtained when $\mathrm{Pb}$ was precipitated as $\mathrm{PbCl}_{2}$. The improvement in the recoveries of the analytes is due to the formation of stable fluorides of impurities in the presence of HF. In the absence of $\mathrm{HF}$, most of the analytes were hydrolyzed leading to poor recoveries.

The percentage separation of lead was also found to improve from $92 \pm 2.0 \%$ (for $\mathrm{PbCl}_{2}$ ) to $99.5 \pm 0.5 \%$ (for PbCIF). This procedure was applied to the determination of $\mathrm{Nb}, \mathrm{Ni}, \mathrm{Sb}, \mathrm{Sn}, \mathrm{Ta}$, and Ti in $\mathrm{Pb}, \mathrm{PbLi}$, and $\mathrm{PbBi}$ samples, and the results are listed in Table III. The method detection limits (MDL) was calculated (in $\mu \mathrm{g} / \mathrm{g}$ in the sample after applying the multiplication factor) as signal equivalent to three times the standard deviation of repeated blank measurements $(n=5)$. The limit of quantification (LOQ) is considered as 10 times the standard deviation of repeated blank measurements. The values obtained are reported as $<\mathrm{LOQ}$.

This procedure requires only acids which are commercially available in pure form. Since no external complexing agent or other reagents are required to be added, the process blank levels were in the lower $\mu \mathrm{g} / \mathrm{g}$ range. The relative standard deviation was found to be in the $1.8-10.2 \%$ range. The concentrations of the impurities in the three samples were at the lower $\mu \mathrm{g} / \mathrm{g}$ levels, except the concentration of $\mathrm{Sn}$ in $\mathrm{PbLi}$ was $22.5 \mu \mathrm{g} / \mathrm{g}$ and of $\mathrm{Ni}$ in $\mathrm{PbBi}$ was $11.1 \mu \mathrm{g} / \mathrm{g}$.

TABLE II

Comparison of Recoveries of $\mathrm{Nb}, \mathrm{Ni}, \mathrm{Sb}, \mathrm{Sn}, \mathrm{Ta}, \mathrm{Ti}$ Using Chloride and Chloride Fluoride Precipitation

\begin{tabular}{|c|c|c|c|}
\hline \multirow[t]{2}{*}{ Element } & \multirow{2}{*}{$\begin{array}{l}\text { Wavelength } \\
\text { (nm) }\end{array}$} & \multicolumn{2}{|c|}{ Recovery (\%) } \\
\hline & & $\begin{array}{c}\mathrm{PbClF} \\
\text { precipitation }(n=3)\end{array}$ & $\begin{array}{l}\qquad \mathrm{PbCl}_{2} \\
\text { precipitation }(\mathrm{n}=3)\end{array}$ \\
\hline $\mathrm{Nb}$ & 269.706 & $93 \pm 2$ & $59 \pm 6$ \\
\hline $\mathrm{Ni}$ & 221.647 & $91 \pm 1$ & $76 \pm 3$ \\
\hline $\mathrm{Sb}$ & 206.833 & $90 \pm 2$ & $65 \pm 7$ \\
\hline Sn & 235.484 & $82 \pm 1$ & $52 \pm 10$ \\
\hline $\mathrm{Ta}$ & 223.980 & $92 \pm 4$ & $52 \pm 7$ \\
\hline $\mathrm{Ti}$ & 334.904 & $94 \pm 2$ & $42 \pm 12$ \\
\hline
\end{tabular}

Note: Uncertainties are expressed as standard deviation of three experiments. 
TABLE III

Concentration of impurities in $\mathrm{Pb}, \mathrm{PbLi}$, and PbBi

\begin{tabular}{cccccc}
\hline Element & $\begin{array}{c}\mathrm{MDL}^{\mathrm{a}} \\
(\mu \mathrm{g} / \mathrm{g})\end{array}$ & Process Blank $^{\mathrm{b}}$ & \multicolumn{3}{c}{$\begin{array}{c}\text { Concentration } \\
(\mu \mathrm{g} / \mathrm{g})(\mathrm{n}=3)\end{array}$} \\
\hline & & & $\mathrm{Pb}$ & $\mathrm{PbLi}$ & $\mathrm{PbBi}$ \\
\hline $\mathrm{Nb}$ & 1.5 & $<5$ & $<5$ & $<5$ & $<5$ \\
$\mathrm{Ni}$ & 0.3 & 2 & $5.4 \pm 0.2$ & $<1$ & $11.1 \pm 0.2$ \\
$\mathrm{Sb}$ & 1.8 & $<6$ & $6.7 \pm 0.2$ & $<6$ & $<6$ \\
$\mathrm{Sn}$ & 1.8 & $<6$ & $9.4 \pm 0.5$ & $22.5 \pm 1.0$ & $<6$ \\
$\mathrm{Ta}$ & 1.5 & $<5$ & $<5$ & $<5$ & $<5$ \\
$\mathrm{Ti}$ & 0.3 & $<1$ & $4.3 \pm 0.3$ & $3.9 \pm 0.4$ & $<1$ \\
\hline
\end{tabular}

Note: Uncertainties are expressed as standard deviation of three experiments.

${ }^{\mathrm{a}} \mathrm{MDL}=$ Method detection limit.

${ }^{b}$ Process Blank of present procedure.

\section{CONCLUSION}

The chloride fluoride precipitation method was used for the separation of lead from trace impurities and for their determination in $\mathrm{Pb}$, $\mathrm{PbLi}$, and $\mathrm{PbBi}$ alloy samples. The percentage separation of $\mathrm{Pb}$ and also the recoveries of the hydrolyzable elements were improved by the addition of HF. The procedure is simple, fast, and better than the $\mathrm{PbCl}_{2}$ precipitation method in recovering the hydrolyzable elements of $\mathrm{Nb}, \mathrm{Ni}, \mathrm{Sb}, \mathrm{Sn}, \mathrm{Ta}$, and $\mathrm{Ti}$.

\section{ACKNOWLEDGMENTS}

The authors thank Dr. J. Arunachalam, Head, CCCM, for his keen interest in this work.

Received June 21, 2012.

\section{REFERENCES}

1. J.U. Knebel, X. Cheng, C.H. Lefhalm, G.Muller, G. Schumacher, J. Konys and H. Glasbrenner, Nuclear Engineering and Design 202, 279 (2000).

2. Y. Dai, F. Barbagallo and F. Groeschel, J. Nucl. Mater. 317, 252 (2003).
3. G. Capannesi, A. Rosada and P. Avino, Microchem. J. 93, 188 (2009).

4. Z. Malkova, K. Nitsch and J. Novak, Anal. Chim. Acta 355, 171 (1997).

5. M. F. Mesko, D. Pozebon, E. M. M. Flores and V. L. Dressler, Anal. Chim. Acta 517, 195 (2004).

6. P. Chaudhuri, C. Danani, V. Chaudhuri, R. Srinivasan, E. Rajendra Kumar and S. P. Deshpande, Fusion Eng. Des. 85, 1966 (2010).

7. H. U. Borgstedt, G. Frees and G. Grechsler, J. Nucl. Mater. 141, 561 (1986).

8. E. Mas de les Valls, L. A. Sedano, L. Batet, I. Ricapito, A. Aiello, O. Gastaldi and F. Gabriel, J. Nucl. Mater. 376, 353 (2008).

9. A. C. Sahayam, Shiuh- Jen Jiang and Chia-Ching Wan, J. Anal. At. Spectrosc. 19, 407 (2004).

10. E. A. Gautier and J. G. Marrero, J. Radioanal. Nucl. Chem. 144, 407 (1990).

11. E. Jackwerth, Pure and Appl. Chem. 51, 1149 (1979).

12. I. Karadzhova, S. Arpadyan and T. Deligeorgiev, Fresenius' Z. Anal. Chem. 333, 9 (1989).

13. H. Onishi, Photometric determination of traces of metals, Part IIA, John Wiley and Sons. Inc., 1986.

14. N. H. Gale, Anal. Chim. Acta, 332 , 15 (1996) 